\title{
Penerapan Teknologi Feminisasi Ikan Betok (Anabas testudineus) yang Dipelihara di Kolam Terpal pada Kelompok Pembudidaya Ikan Haru Mangat Kota Palangka Raya
}

\section{The Application of Feminization Females Technology (Anabas testudineus) Maintained in Tarpaulin Ponds in the Haru Mangat Fish Farmers Group in Palangka Raya City}

Mohamad Rozik
Ummi Suraya*
Muhamad Noor Yasin
Department of Fisheries, Universitas
Palangka Raya, Palangka Raya,
Central Kalimantan, Indonesia
'email: surayaummi@yahoo.co.id
Kata Kunci
Ikan Betok
Teknologi Feminisasi Ikan
Kelompok Pembudidaya Ikan
Keywords:
Betok Fish
Fish Feminization Technology
Fish Cultivation Group
Received: November 2019
Accepted: March 2020
Published: June 2020

\begin{abstract}
Abstrak
Kegiatan program Pengabdian Pada Masyarakat (PPM) yang akan dilaksanakan pada kelompok tani pembudidaya ikan Haru Mangat berupa teknologi budidaya ikan betok (Anabas testudineus) dengan sistem intensif melalui proses feminisasi pada ikan betok, dengan tujuan untuk meningkatkan keterampilan dan pengetahuan masyarakat khalayak sasaran, sedangkan manfaatnya agar terciptanya usaha mikro baru bagi mitra sasaran. Metode kegiatan dengan metode observasi partisipan langsung terhadap kegiatan observasi dan wawancara, pelaksanan pelatihan dan bimbingan teknis serta kegiatan demplot area percontohan. Luaran kegiatan program Pengabdian Pada Masyarakat pada kelompok pembudidaya ikan Haru Mangat terutama para pembudidaya ikan dalam membudidayakan ikan Betok sistem intensif di kolam dapat dengan mudah memahami dan mengetahui teknik pemeliharaan ikan Betok dengan teknologi feminisasi. Kelompok pembudidaya ikan tersebut sangat berminat untuk membudidayakannya dengan menggunakan kolam terpal.
\end{abstract}

\begin{abstract}
Community Service Program (PPM) activities that will be carried out in the Haru Mangat fish farmer group in the form of technology for Betab Cultivation (Anabas testudineus) with an intensive system through the feminization process in the fish, to increase the skills and knowledge of the target audience, while the benefits are to create new micro-businesses for target partners. The method of activities with the method of direct participant observation of the activities of observation and interviews, implementation of training and technical guidance, and demonstration plot demonstration activities. The outputs of the Community Service program activities in the Haru Mangat fish cultivator group especially fish farmers in cultivating Betok fish intensive systems in ponds can easily understand and know the techniques of raising Betok fish with feminization technology. The fish cultivator group is very interested to cultivate it using tarpaulin ponds.
\end{abstract}

(c) 2020 Mohamad Rozik, Ummi Suraya, Muhamad Noor Yasin. Published by Institute for Research and Community Services Universitas Muhammadiyah Palangkaraya. This is Open Access article under the CC-BYSA License (http://creativecommons.org/licenses/by-sa/4.0/). DOI: https://doi.org/10.33084/pengabdianmu.v5i3.1095

\section{PENDAHULUAN}

Kebutuhan produk hasil perairan dari berbagai jenis ikan terus meningkat sejalan dengan pertambahan penduduk, dimana rata-rata penduduk Indonesia mengkonsumsi daging ikan $43,9 \mathrm{~kg} / \mathrm{kapita} / \mathrm{tahun}$ (Virgantari et al., 2011). Kendala yang dihadapi untuk pengembangan akuakultur tidak hanya menurunnya mutu lingkungan dan terbatasnya areal budidaya, akan tetapi ketersediaan benih yang tepat jumlah, tepat mutu, tepat waktu dan tepat harga menjadi salah satu kendala dalam program intersifikasi budidaya ikan (Hermawan, 2017). 
Ikan betok merupakan salah satu jenis ikan tawar yang banyak ditemukan disekitar sungai, aduk ataupun danau. Ikan betok ini juga adalah jenis ikan karnivora ataupun ikan pemangsa. Di alam, pemijahan ikan Betok terjadi sekali dalam setahun pada musim penghujan dan ikan ini termasuk ikan yang sangat sulit memijah secara alami dalam lingkungan budidaya (Anggra et al., 2013). Biasanya pemijahan ikan betok ini dikerjakan dengan cara buatan yaitu dengan cara kawin suntik. Dalam sekali musim kawin, ikan betok bisa dipijahkan sebanyak 3 kali dengan menghasilkan sekitar 5.00015.000 butir telur saja (Maidie et al., 2015). Untuk mengatasi kendala tersebut salah satu upaya yang dapat dilakukan adalah meningkatkan produktivitas budidaya melalui pemijahan dengan rangsangan hormonal untuk reproduksi ikan betok dalam rangka penyediaan benih secara kontinu (Yasin, 2013).

Permasalahan utama pada kegiatan budidaya ikan Betok sistem intensif belum dapat mengoptimalkan hasil/produk budidaya. Guna mendukung kondisi tersebut diperlukan benih yang memiliki karakter tertentu dan menguntungkan dalam usaha budidaya. Pada umumnya kebutuhan akan jumlah benih relatif dapat dipenuhi akan tetapi dari segi kualitas masih perlu diperbaiki agar hasilnya sesuai dengan harapan. Budidaya ikan Betok secara intensif dengan teknologi feminisasi ini merupakan salah satu solusi agar dapat mencapai ikan Betok dengan ukuran konsumsi sesuai keinginan pasar dalam waktu yang cepat (Suraya et al., 2019).

Kegiatan pengabdian ini akan rencananya akan dilakukan di Kelompok tani Pembudidaya ikan Haru Mangat di Kelurahan Menteng Kecamatan Jekan Raya, Kota Palangka Raya yang merupakan salah satu petani ikan pembudidaya yang ada di Kelurahan Menteng Kota Palangka Raya.
Rencana kegiatan dalam rangka meningkatkan pengetahuan dan keterampilan masyarakat petani ikan pembudidaya sebagai khalayak sasaran dilakukan melalui kegiatan pendidikan masyarakat berupa penerapan IPTEKS, kegiatan observasi dan wawancara langsung, pembuatan demplot area dan pembinaan secara teknis kepada masyarakat/petani ikan pembudidaya (Nasir \& Made, 2018). Kegiatan ini nantinya diharapkan dapat meningkatkan pengetahuan dan keterampilan mitra sasaran dalam bidang usaha skala mikro yakni teknologi budidaya ikan Betok secara intensif di kolam terpal (Miranti et al., 2017).

Tujuan kegiatan yang ingin dicapai dari kegiatan yaitu diharapkan dapat memberikan pengetahuan dan keterampilan kepada mitra kelompok pembudidaya ikan Haru Mangat di Kelurahan Menteng Kecamatan Jekan Raya dalam bidang manajemen usaha budidaya Ikan Betok di Kolam terpal dengan sistem teknologi feminimisasi. Sedangkan manfaatnya adalah adanya pembinaan kelompok pembudidaya ikan Haru Mangat di Kelurahan Menteng Kecamatan Jekan Raya Kota Palangka Raya agar memiliki usaha usaha skala mikro budidaya ikan secara intensif di Kolam terpal serta memiliki keterampilan tentang penerapan Feminisasi Ikan Betok.

\section{METODOLOGI}

Kegiatan pelaksanaan Pengabdian Pada Masyarakat ini dilakukan dengan melibatkan mitra sasaran pada kegiatan penyuluhan dan pelatihan yakni kesepakatan menentukan waktu dan tempat pelaksanaan kegiatan, menentukan peserta yang mengikuti kegiatan program Pengabdian Pada Masyarakat (PPM). Metode pelaksanaan yang ditawarkan ini merupakan solusi untuk memecahkan permasalahan petani ikan pembudidaya ikan Haru Mangat dengan cara wawancara langsung, demplot area percontohan, 
pelatihan dan bimbingan teknis secara intensif sehingga dapat meningkatkan pengetahuan khalayak sasaran tentang teknologi budidaya ikan Betok. Penerapan IPTEKS yang ditawarkan kepada khalayak sasaran sebagai aplikasi dari dasar teori tentang budidaya ikan betok sistem feminisasi ikan Betok.

\section{HASIL DAN PEMBAHASAN}

Dalam hal ini kegiatan observasi dan wawancara pada kegiatan Program Kemitraan Wilayah di Kelurahan Menteng adalah pembinaan kelompok petani ikan pembudidaya ikan Haru Mangat dalam membudidayakan ikan betok dengan sistem penerapan teknologi feminisasi pada kolam terpal. Berdasarkan hasil wawancara ternyata banyak yang tidak mengetahui teknik budidaya ikan betok secara teknologi feminisasi ini.

Dari kelompok masyarakat pembudidaya ikan Haru Mangat rata-rata kelompok masyarakat ini banyak pola usaha masyarakatnya sebagai petani holtikultura sehingga banyak yang belum tahu sistem penerapan teknologi feminisasi pada kolam terpal yang dapat meningkatkan pendapatan keluarga.

Pelatihan ini dilakukan bersama dengan mitra yang dihadiri oleh 20 orang yang terdiri antara lain pemilik usaha dan para pekerjanya. Dimana pekerja tersebut adalah anggota kelompok budidaya ikan Haru Mangat warga disekeliling tempat usaha. Pelatihan berjalan lancar dan para peserta antusias dalam kegiatan tersebut. Pelatihan ini menggunakan bahan- bahan dari tim dan peralatan sebagian dari tim dan sebagian dari mitra Kegiatan ini dilakukan penyuluhan dan pelatihan dengan tujuan memberikan pengetahuan kepada pemilik usaha dan karyawannya tentang penerapam teknologi feminisasi ikan betok di kolam terpal. Kegiatan ini juga disertai dengan pembuatan kolam terpal. Pembuatan kolam berlangsung selama dua hari. Selama pembuatan kolam mitra juga dilibatkan. Pelibatan ini bermaksud sekaligus memberikan pengetahuan kepada mitra tentang beberapa fungsi dan manfaat kolam terpal. Materi bimbingan teknis yang dibuat secara praktis dan diberikan melalui hardcopy kemudian disampaikan melalui sistem ceramah lapangan, diskusi dan sharing. Pemahaman dan daya serap masyarakat petani pembudidaya ikan ternyata dapat dengan mudah mengetahui teknik pemeliharaan ikan sistem penerapan teknologi feminisasi ikan betok pada kolam terpal dan berminat untuk memelihara ikan betok dengan menggunakan kolam terpal (Helmizuryani \& Khotimah, 2016; Maidie et al., 2015). Dari beberapa kelompok petani ikan pembudidaya ikan Haru Mangat pada tahun-tahun mendatang berkeinginan untuk mencoba berusaha memelihara beberapa jenis ikan lokal lainnya dengan kolam terpal.

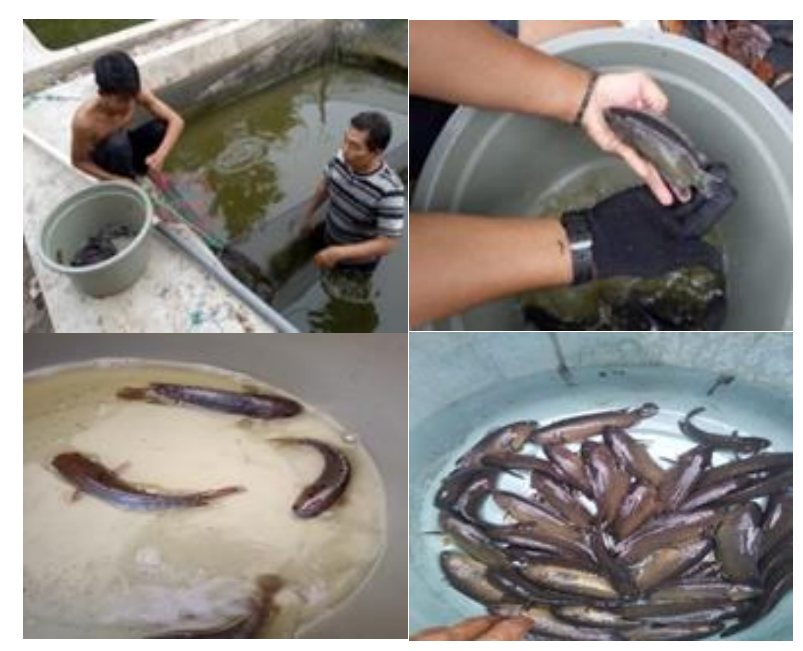

Gambar 1. Penyeleksian dan pengambilan indukan ikan betok

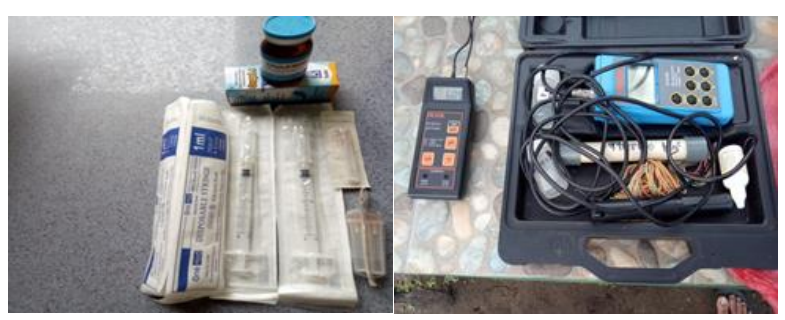

Gambar 2. Peralatan feminimisasi ikan betok 
Demplot percontohan kolam terpal dibuatkan 1 buah untuk kelompok pembudidaya ikan Haru Mangat. Demplot tersebut merupakan bentuk kegiatan dari program Pengabdian Kemitraan wilayah (PKW) yang dilaksanakan di Kelurahan Menteng. Teknologi pembuatan kolam terpal digunakan sebagai contoh untuk budidaya ikan Betok yang dapat dijadikan percontohan bagi pembudidaya ikan lainnya. Teknik budidaya ikan Betok di kolam terpal meliputi teknik penebaran benih ikan, pemberian pakan, penanganan kualitas air dan kesehatan ikan yang diharapkan sudah dapat mereka lakukan.

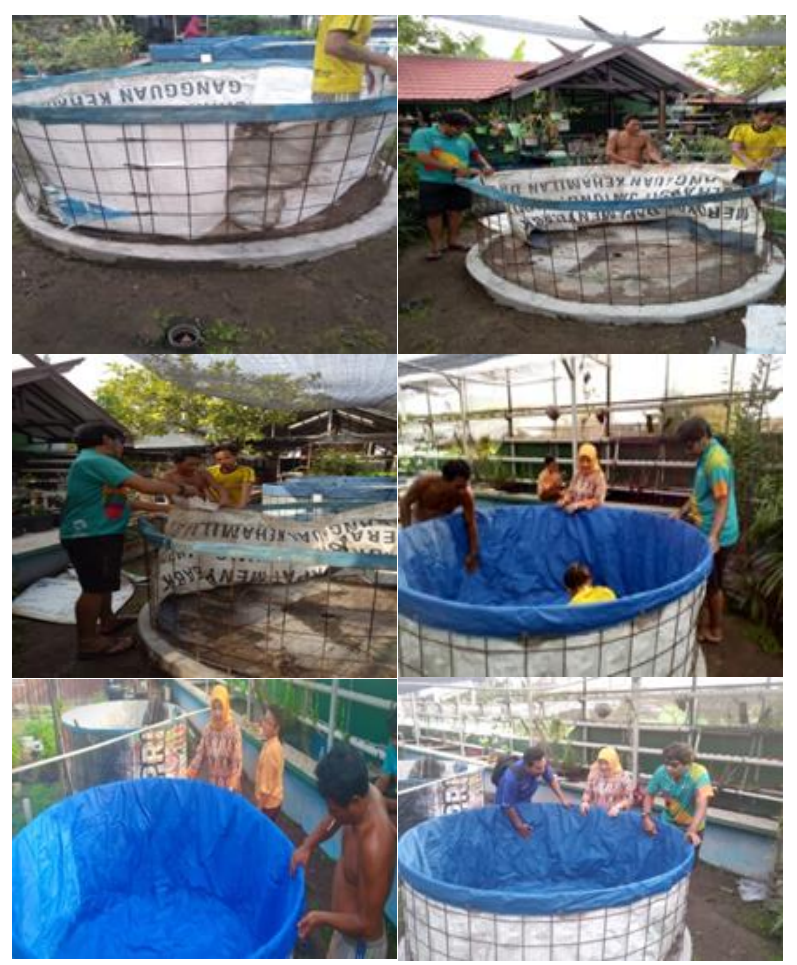

Gambar 3. Proses pembuatan kolam terpal

Penerapan teknologi feminisasi pada ikan Betok di kelompok pembudidaya ikan Haru Mangat dengan melakukan pelatihan dan demonstrasi cara pemberian hormon estradiol-17 $\beta$. Estradiol-17 $\beta$ adalah hormon estrogenalami yang telah terbukti efektif mengarahkan kelamin betina (pembetinaan). Pemberian hormon estradiol-17 $\beta$ secara langsung dapat dilakukan dengan cara oral (Kurniasih et al., 2006) dan perendaman
(Grandi et al., 2007). Bila dilihat dari segi efisiensi waktu dan penanganan serta jumlah hormon yang digunakan, maka cara yang paling baik adalah dengan sistem perendaman pada larva ikan betok yang telah berumur tujuh hari. Pemberian hormon estradiol-17 $\beta$ melalui perendaman embrio dapat mening katkan persentase jenis kelamin betina ikan betok sebesar $95 \%$ dengan dosis 25-400 $\mu \mathrm{g} / \mathrm{L}$ dan waktu perendaman 6-8 jam.

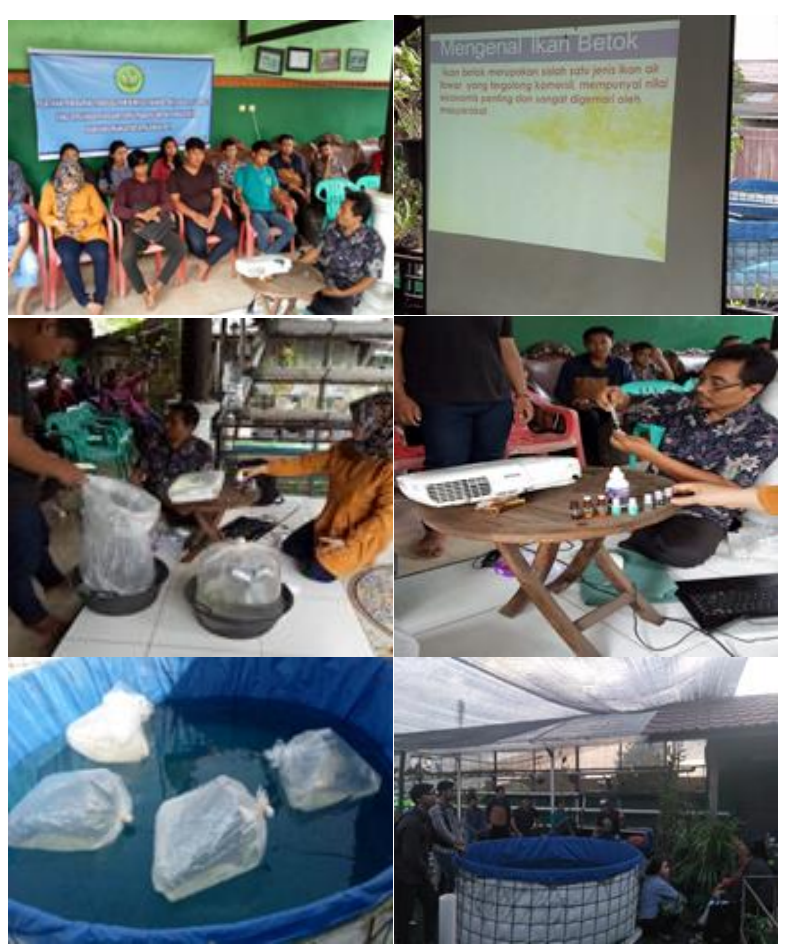

Gambar 4. Demonstrasi kegiatan, penyuluhan dan pelatihan

\section{KESIMPULAN}

Kelompok masyarakat pembudidaya ikan dan mitra yang mengikuti kegiatan Program Kemitraan Wilayah $(\mathrm{PKW})$, sudah memiliki pengetahuan penerapan teknologi feminisasi ikan betok pada kolam terpal dan mengetahui prospek usaha budidaya ikan betok yang dapat meningkatkan pendapatan keluarga dimana usaha budidaya ikan betok ini akan memberikan keuntungan / hasil yang maksimal apabila dilakukan secara intensif kontinu dan berkelanjutan. Kelompok pembudidaya ikan Haru Mangat ini dapat menerapkan secara benar dan konsisten agar diperoleh hasil yang 
memuaskan dengan peningkatan produksi dan kualitas ikan Betok sesuai harapan datang terutama sistem teknologi pembenihanikan untuk pengembangan usaha pembesaran ikan Betok. Selain itu sangat mengharapkan dana pendamping untuk mengembangkan usaha pemeliharaan jenis ikan lokal lainnya dengan menggunakan kolam terpal sehingga bisa mengangkat perekonomian keluarga masyarakat.

\section{REFERENSI}

Anggra, A., Muslim, Muslimin, B. 2013. Kelangsungan Hidup Dan Pertumbuhan Larva Ikan Betok (Anabas testudineus) Yang Di Beri Pelet Dengan Dosis Berbeda. Fiseries: Jurnal Penelitian Ilmu-Imu Perairan dan Perikanan. 2(1):21-25.

Grandi, G., Giovannini, S., Chicca, M. 2007. Gonadogenesis in early developmental stages of Acipenser naccarii and influence of estrogen immersion on feminization. Journal of Applied Ichthyology.

23(1):3-8. https://doi.org/10.1111/j.1439-

0426.2006.00819.x

Helmizuryani, Khotimah, K. 2016. Produktivitas Feminimisasi Larva Ikan Betok (ANABAS TESTUDINEUS) Menggunakan Ekstrak Sayur-Sayuran Dengan Metode Dipping. Fiseries: Jurnal Penelitian Ilmu-Ilmu Perairan dan Perikanan. 5(1):19-24.

Hermawan, A. 2017. Kapasitas dan Kinerja Pengelolaan Usaha Akuakultur Anggota Kelompok Pembudidaya Ikan di Kabupaten Tasikmalaya. Jurnal Penyuluhan Perikanan dan Kelautan. 11(3):160-176. https://doi.org/10.33378/jppik.v11i3.93

Kurniasih, T., Arifin, O.Z., Marizal. 2006. Feminisasi Nila (GIFT), Oreochromis sp. Menggunakan Hormon Estradiol 17- $\beta$. Jurnal Perikanan Universitas Gadjah Mada. 8(1):74-80. https://doi.org/10.22146/jfs.166

Maidie, A., Sumoharjo, Asra, S.W., Ramadhan, M., Hidayanto, D.W. 2015. Pengembangan Pembenihan Ikan Betok (Anabas testudineus) Untuk Skala Rumah Tangga. Media Akuakultur. 10(1):31-37. http://dx.doi.org/10.15578/ma.10.1.2015.3137

Miranti, F., Muslim, Yulisman. 2017. Pertumbuhan Dan Kelangsungan Hidup Larva Ikan Betok (Anabas testudineus) Yang Diberi Pencahayaan Dengan Lama Waktu Berbeda. JARI : Jurnal Akuakultur Rawa Indonesia. 5(1):3344. https://doi.org/10.36706/jari.v5i1.5806

Nasir, B., Made, U. 2018. Pemberdayaan Masyarakat Dalam Mengelola Potensi Sumberdaya Pertanian Untuk Meningkatkan Pendapatan Dan Kesejahteraan Masyarakat Melalui Pendampingan Mahasiswa KKN-PPM Di Kecamatan Gumbasa Kabupaten Sigi. Pengabdian Pada Masyarakat. 6(10):26-36.

Suraya, U., Yasin, M.N., Rozik, M. 2019. Penerapan Jantanisasi Ikan Nila (Oreochromis niloticus) di Kelompok Tani Kahayan Mina Kelurahan Pahandut Seberang Kecamatan Pahandut Kota Palangka Raya. PengabdianMu: Jurnal Ilmiah Pengabdian Kepada Masyarakat. 4(1):6-9. https://doi.org/10.33084/pengabdianmu.v4i 1.450

Virgantari, F., Daryanto, A., Harianto, Kuntjoro, S.U. 2011. Dinamika Konsumsi Produk Perikanan di Indonesia. Ekologia: Jurnal Ilmiah Ilmu Dasar dan Lingkungan Hidup. 11(2):22-30. https://doi.org/10.33751/ekol.v11i2.257

Yasin, M.N. 2013. Pengaruh Level Dosis Hormon Perangsang Yang Berbeda Pada Pemijahan Ikan Betok (Anabas testudineus Bloch) Di Media Air Gambut. Jurnal Ilmu Hewani Tropika. 2(2):52-56. 